\title{
The Recent Developmental Platforms and Potential Targets of SARS CoV-2 Vaccines: A Comprehensive Review
}

\author{
Sonam Bhutia ${ }^{1, *}$, Bibhuti Bhusan Kakoti ${ }^{2}$, Prosanta Pal ${ }^{3}$ \\ ${ }^{1}$ Government Pharmacy College, Sajong, Government of Sikkim, Sikkim University East Sikkim, India \\ ${ }^{2}$ Department of Pharmaceutical Sciences, Dibrugarh University, Dibrugarh, Assam, Pin, India \\ ${ }^{3}$ Department of Pharmaceutical Technology, University of North Bengal, West Bengal, India
}

Received May 28, 2021; Revised August 5, 2021; Accepted October 28, 2021

\section{Cite This Paper in the following Citation Styles}

(a): [1] Sonam Bhutia, Bibhuti Bhusan Kakoti, Prosanta Pal, "The Recent Developmental Platforms and Potential Targets of SARS CoV-2 Vaccines: A Comprehensive Review," Advances in Pharmacology and Pharmacy, Vol. 9, No. 4, pp. 127 - 138, 2021. DOI: 10.13189/app.2021.090406.

(b): Sonam Bhutia, Bibhuti Bhusan Kakoti, Prosanta Pal (2021). The Recent Developmental Platforms and Potential Targets of SARS CoV-2 Vaccines: A Comprehensive Review. Advances in Pharmacology and Pharmacy, 9(4), 127 - 138. DOI: 10.13189/app.2021.090406.

Copyright $\bigcirc 2021$ by authors, all rights reserved. Authors agree that this article remains permanently open access under the terms of the Creative Commons Attribution License 4.0 International License

\begin{abstract}
The novel coronavirus disease is a rapidly spreading infection caused by recently discovered different variants of SARS CoV-2 viruses, causing mild to severe respiratory symptoms in the majority of people. The Coronavirus disease 2019 pandemic has spread almost all the nooks and corners of the world. There are significant possible approaches pharmaceutically to fight against COVID-19. Original full-text research articles were searched online in PubMed, ScienceDirect, ResearchGate, Google Scholar, Core and Wiley Online Library. Scientists throughout the world are working on different platforms and targeting certain proteins moieties against SARS CoV-2 for the development of methods of safety, efficacy and potential vaccine candidates. Many candidates showed efficacy in In-vitro studies but relatively few clinical studies proceeded through different vaccine development platforms, such as entire virus vaccines, plant-based and nucleic acid vaccines, recombinant protein subunit vaccines. This review study provides a short description of SARS-CoV-2 characteristics and deals with recent developments in the design of attempts
\end{abstract}

to produce vaccines to combat COVID-19.

Keywords Vaccines Development, SARS CoV-2, Platforms, Potential Targets, Recent Techniques and Processes

\section{Introduction}

The SARS-CoV is a single-strand protected virus lipid membrane (M, E, \& S glycoproteins) which may be enabled by ACE2 as a functional receptor that mediates viral entrance into host target cells [1,2]. An important stimulator for the activation of neutralising antibodies is the $\mathrm{S}$ protein. In addition, the RBD (Receptor Binding Domain) in the S1 subunit of the S protein consists of several neutralising epitope conformation structures that are critical markers for the production and development of vaccines (Fig 1-cen.acs.org). 


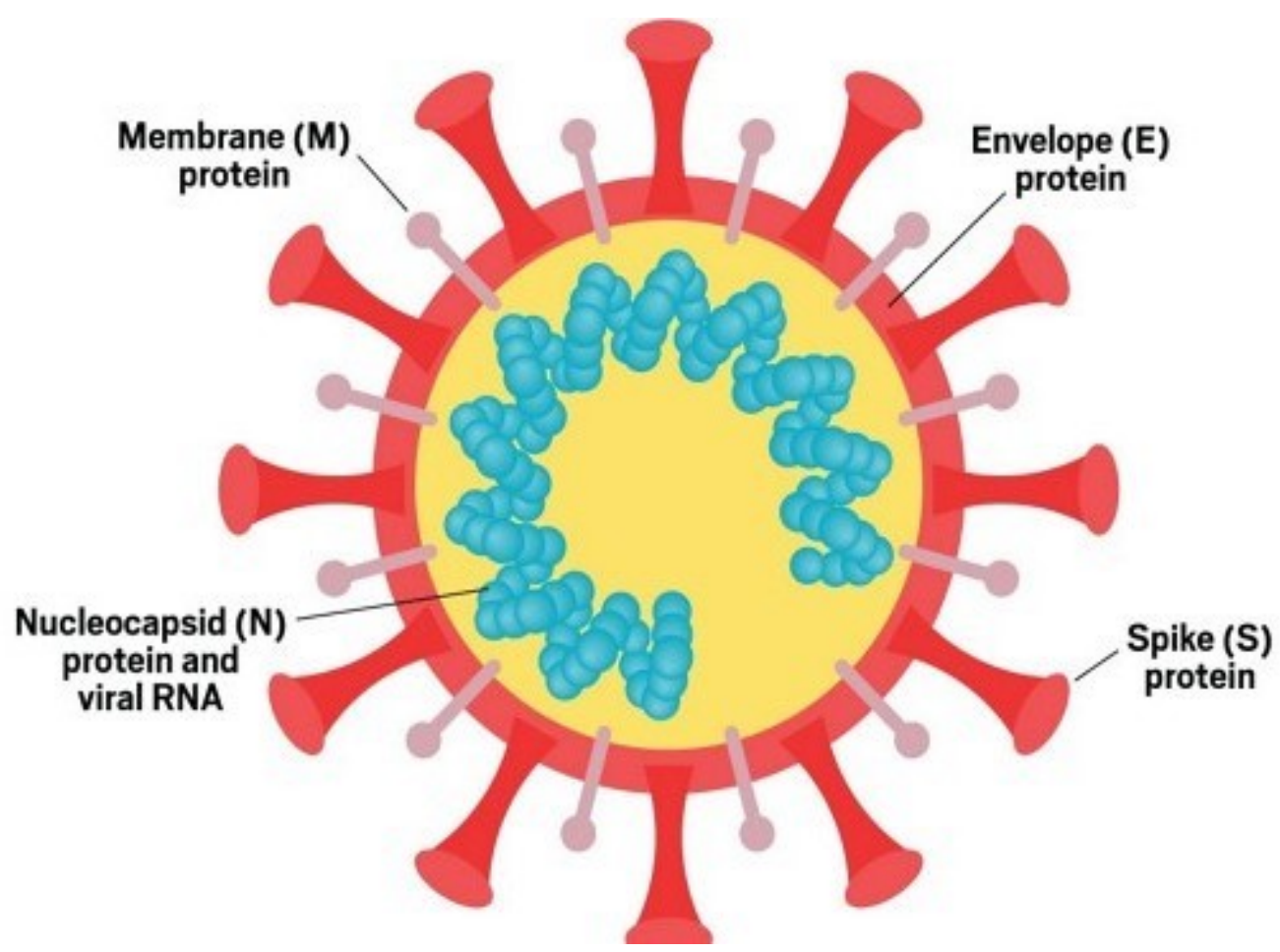

Figure 1. SARS-CoV-2 has 4 structural proteins (top): $\mathrm{M}$ and $\mathrm{E}$ proteins, forming the viral envelope; N-protein binding to RNA genome of the virus; and $\mathrm{S}$ protein binding to human receptors. Source: cen.acs.org

To create NSP-CAS signalling modules, NSP proteins are unusual domain with no catalytic activity for nucleotide exchange factors. NPS proteins mediate membrane reconfiguration, which results in dual membrane formation of vesicles where there is viral transcription and replication from the rough endoplasmic reticulum (Fig 2- Funk et al., 2020). Although SARS-CoV-2 binds to the ACE2 receptor, the DPP4 (dipeptidyl peptidase 4, often referred to as CD26) cellular receptor is the target of MERS-S in the N-terminal surface subunit via RBDMERS-molecular CoV's interaction with hCD26 was delineated. S1 domain detects hCD26 with a centre and an external sub-domain which is located in a C-terminal 240- residue RBD [3-5]. The binding of the S1 unit surface was documented to promote the binding of viruses to the target host cell surface. In addition, at both $\mathrm{S} 1 / \mathrm{S} 2$ as well as S2 sites, $\mathrm{S}$ protein cleavage is related to priming processes via cellular proteases guided by the $\mathrm{S} 2$ subunit, which involves virus fusion and cellular membranes. The involvement of SARS-S with ACE2 as that of the access receptor [6] contributes to the use of cell serine protease-CSP TMPRSS2 for S-protein priming $[7,8]$. In a CT scan, the lungs of seriously ill COVID-19 patients appear opaque. SARS-CoV-2 enters the body through the nose, mouth, or eyes and travels to the alveoli, where ACE2 receptors are abundant. Alveoli are balloon-shaped structures which exist in the body. Different cells and chemicals are engaged in both protective immunity and inflammation in any lung infection. Invading SARS-CoV-2 interacts with the epithelium of the tracheobronchial and alveolar tubes, causing cell death (apoptosis/necrosis). Both the endothelium and epithelial layers suffer from the injury, which compromises their tight barrier integrity. The epithelium is made up of a monolayer of alveolar type I and type II cells, which are responsible for gas exchange and surfactant synthesis, respectively. These functions maintain the lungs' air spaces dry. Intrinsic lymphocytes such as monocytes, neutrophils, immature macrophages, and dendritic cells are recruited to injured cells by danger signals such as radical oxygen/nitrogen species. Immune cells, epithelial cells, and fibroblast cells secrete excessive amounts of pro-inflammatory cytokines and chemokines in response to unregulated excitation, which functions as a causal factor for epithelial cell death [9]. 


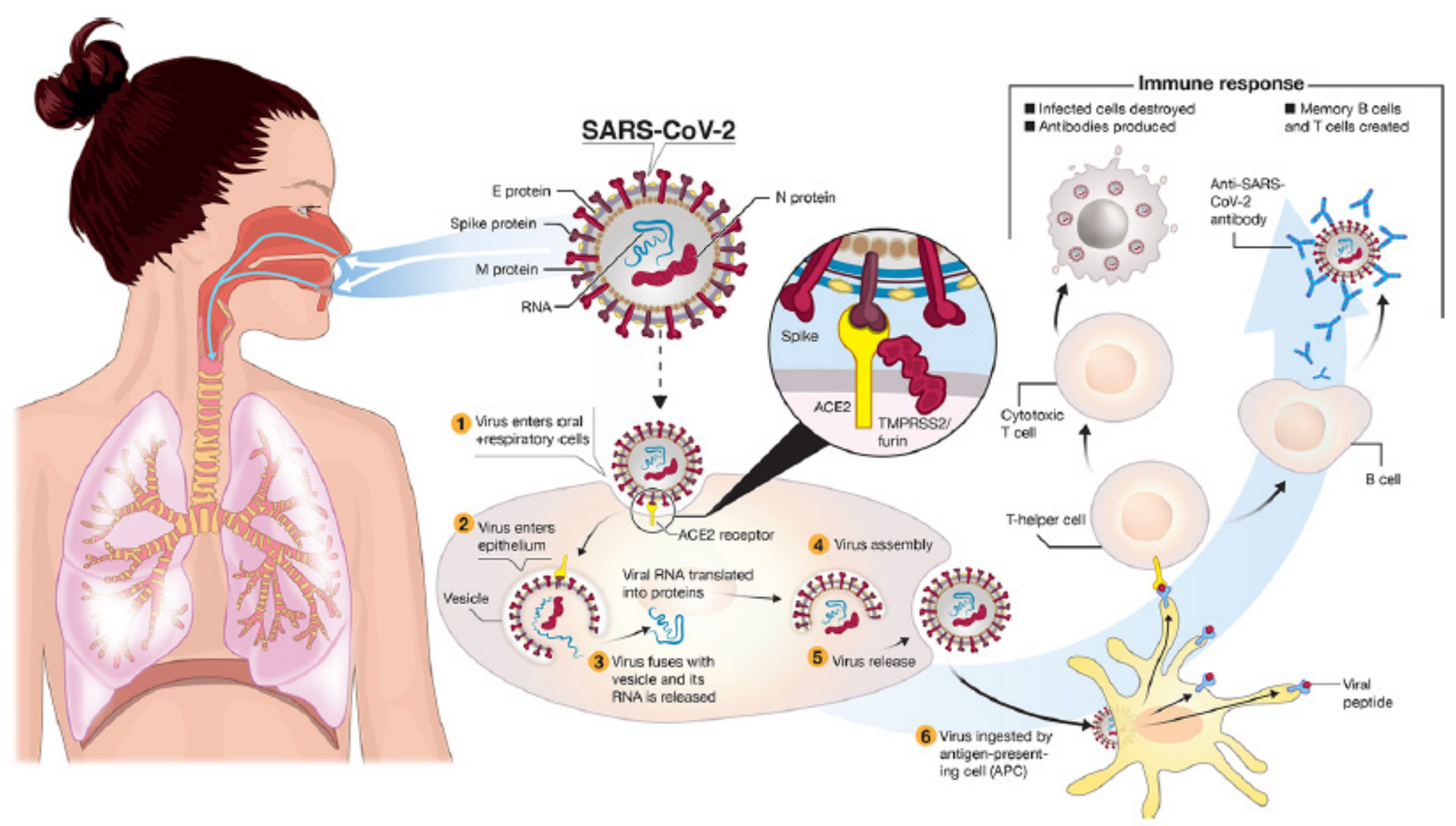

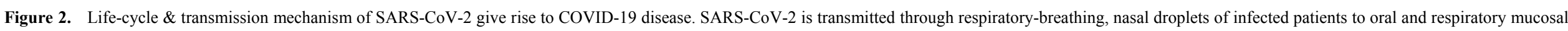
cells. Source: Funk et al., 2020 


\section{Potential Therapeutic Targets for Vaccine Development}

The structural proteins which cover the SARS-CoV-2 surface are among the more likely candidates for vaccination. These involve the protein $\mathrm{S}$ of the envelope pulse, the protein $\mathrm{E}$ of the small envelope, the protein $\mathrm{M}$ of the matrix and the protein $\mathrm{N}$ of the non-exposed nucleocapsid. In an early analysis of recombinant vectors that express the SRS-CoV-2 S protein, this protein was shown to be highly immunogenic and defensive against SARS-CoV challenge in hamsters, while the E, M, \& N, proteins, on the other hand, a neutralising antibody reaction or defensive immunity has not significantly contributed [10]. The analysis on human-neutralizing antibodies from unusual memory B cells of MERS-CoVor SARS-CoV-infected persons have presented the indication of the important function of $\mathrm{S}$ protein in coronavirus-infection mitigation $[11,12]$. In some studies, SARS-CoV antibodies against the S-protein impede virus penetration in host cells have been successfully detected. SARS-CoV S has even more recently been discovered to elicit polyclonal antibody responses and to vigorously neutralise the entrance of SARS-CoV-2 S-mediated cells, thereby promoting the use of the molecular target for immunotherapy as well as vaccination [13]. The structural studies of complex antibodies SARS-CoV $\mathrm{S}$ and MERS-CoV $S$ provide insights into the competitive inhibition mechanism of the host receptor. RBD was discovered to be highly attached to ACE2 receptors in the SARS-CoV-2 S protein [14]. RBD-specific SARS-CoV antibodies cross-react with the protein SARSCoV-2, SARS-CoV-2 RBD, and SARS-CoVRBD-induced antisera neutralised SARSCoV-2 which provides further indication that targeting SARS-CoV-2 protein with a vaccine in this domain may help in preventing [15]. In the outer state, that is, the primary state of the $\mathrm{S}$ protein, the receptor-binding domain of the $\mathrm{S}$ protein binds to the ACE2 starting virus entrance into the host cell. After all, proteolytic splitting of the $\mathrm{S}$ protein by cathepsin proteases, furin-like, and trypsin-like as involves the effective virus replication of the RBD of $\mathrm{S}$ protein to ACE2 [16,17].

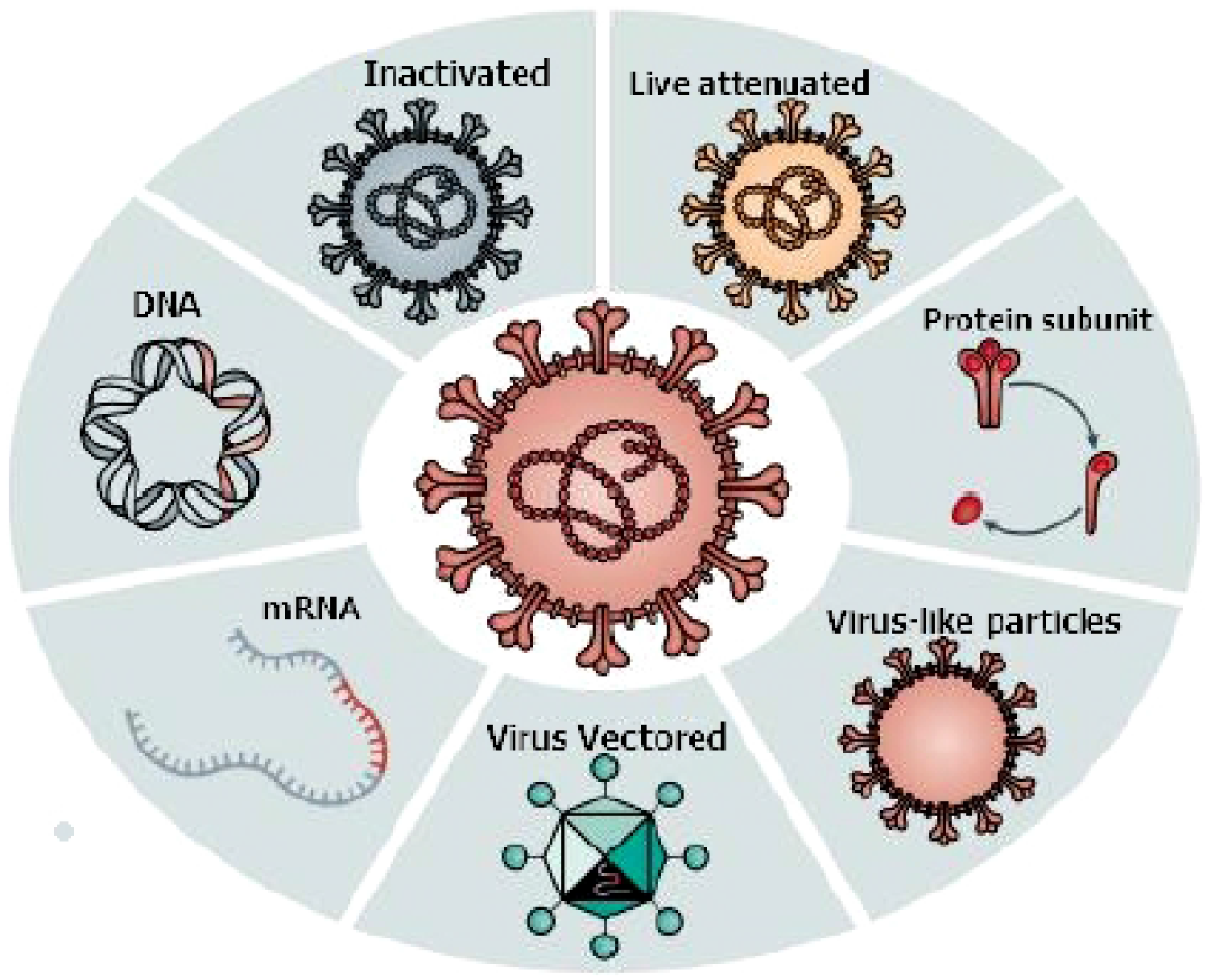

Figure 3. The seven possible strategies being explored as vaccines development for COVID-19. Source: Dai L et al., 2020 


\subsection{Targeting Viral Entry}

The SARS-CoV-2 entrance into host cells can be condensed into a multi-stage process consisting of ACE2 as well as $\mathrm{S} 1$ proteolytic cleavage, the binding of $\mathrm{S}$ viral proteins to the ACE2 host cell receptors by RBD in the S1 subunit, the fusion and the endocytosis of the $\mathrm{S}$ virus with the Host cell membrane. The RNA viral release into the host cell cytoplasm and viral protein synthesis is then followed by this. In the ER/Golgi apparatus, newly synthesised viral proteins, as well as viral RNA, are arranged into virions and from the host cellsthen excreted by exocytosis. Various initiatives are undertaken to address certain measures, including those related to the entrance of virus cells [18] (Fig 3).

\subsection{TMPRSS2 Inhibitors}

Prevailing data indicate that $\mathrm{S}$ protein and ACE2 receptor proteolytic cleavage is a necessary step to block the entrance of SARS-CoV-2 into the host cells [19]. Data in the mice model show the elimination of virus close to SARS-CoV-2 of TMPRSS2 gene abrogates to indicate the critical role of that protease in viral entry [20]. Nafamostatmesylate and Camostatmesylateare commercially available serine protease inhibitors that are presently being utilizedto cure cystic fibrosisandchronic pancreatitis. As shown in preclinical trials that camostatmesylate treatment prevents the entry into the epithelial cells of SARS-CoV-2 [21]. Likewise, in an in vitro assay, the TMPRSS2-dependent MERS-CoV host cell membrane fusion is reduced by nafamostat. Scientific data are confined to case reports of clinical effectiveness in COVID-19 sufferers [22,23]. In the treatment of COVID-19 patients, many randomized clinical studies evaluating the potential efficacy of camostat and more robust nafamostat.

\subsection{Recombinant ACE2}

This is because the ACE receptors are occupied, thus its accessibility for SARS-CoV-2 binding is attenuated. Administration of the recombinant ACE2 is therefore needed to neutralize as well as bind the capability of the viral S protein to bind to cells via boosting circulating ACE2 receptors. The approach should thus minimize viral entrance into the host cell and alleviate the phenotypic effects. The effectiveness of recombinant human ACE has been shown in studies in cultured cells and organoid technologies inhibiting cell entry SARS-CoV-2 [24].

\subsection{Neutralizing Antibodies from Convalescent Plasma}

The host B cells develop several neutralising antibodies in the COVID-19 patients targeting numerous viral proteins epitopes. Such antibodies are removed, washed and utilized for medicinal uses. The existence of several antibodies enables the potential loss of efficacy to be avoided by the use of a single antibody cocktail. The effectiveness loss is usually attributed to a loss of target antigenicity because of replication mutagenesis, which leads to the loss of targeted epitope antigenicity by affecting protein structure and overall avoidance of viral penetration is the key role of neutralising antibodies. It is in contradistinction to viral protease blockers targeting andnucleoside analogues viral replication and development of virions within the host cell [25].Preliminary trials in a few individuals have shown positive effects on viral load, radiological detection of plasma transfusion and recovery of a sick patient with extreme COVID-19 from patients recovering from COVID-19 [26-27]. However, the positive benefits have not been seen consistently. There are presently more than 50 clinical trials in progress, including two dozen phase III trials and two randomized studies with undetermined results [28].

\subsection{Targeting Endocytosis}

There is no known exact membrane dealing of SARS-CoV-2 in the host cell. Nonetheless, endocytic pathway tracts are involved that may be targeted preventing viral entrance. A variety of presently available medicines were found to target the endo-cytic pathways, primarily through endosome acidification. Among other items, the list contains hydroxychloroquine, chloroquine, chlorpromazine, amiloride as well as sertraline. Based on the first outcomes and decreases in viral load, the usage of chloroquine and its mildly hazardous variant hydroxychloroquine was very important [29]. However, in the non-appearance of convincing scientific proof of effectiveness in observation investigational statics as well as small-scale randomised clinical studies, the preliminary excitement for the possible effectiveness of hydroxychloroquine (only or azithromycin antibiotic combination) in the therapeutic care of COVID-19 patients was diminished [30]. In the case of the hydroxychloroquine group, the 28-day mortality was 25.7 percent in contrast to 23.5 percent in the normal treatment group (danger risk ratio: 1.11, 95\%CI: 0.98-1.26). The shortfall of effectiveness, found with these medications, is further exacerbated by the QT prolongation as well as possibly pro-arrhythmic adverse reactions. Although many trials have been terminated, many major randomised clinical investigations are still underway to evaluate the COVID-19 patients' treatment effectiveness with Hydroxychloroquine [31].

\subsection{Downstream Pathways and SARS-CoV-2}

To avoid, attenuate, or partially reverse the response of the host cells to SARS-CoV-2 infection, a wide range of pharmacological as well as non-pharmacological 
developments are used. The cytokine storm, designated by a marked-up gradation of cytotoxic \&pro-inflammatory cytokines likeTNF-a,IL1, IL6, IL10, and IFN-g, among others is a notable phenotypic characteristic [32]. Subsequently, specific cytokine inhibitors, like tocilizumab, an IL6 monoclonal antibody are utilized in the care of COVID-19 patients. Preliminary observational findings suggest that tocilizumab therapy is related to better laboratory and clinical outcomes, together with mechanical ventilation risk and hospital-related [33]. Although the unpublished study of phase III randomised double-blind clinical investigational trial (COVACTA) manifested no positive 4-week death results among tocilizumab or placebo-treated patients.

\subsection{Messenger RNA Vaccines}

The mRNA vaccine is the most recommended as the best and less time-taking way towards producing a COVID-19 vaccine. RNA vaccinations are now the most effective way to fight COVID-19. The main target of RNA vaccinations is the $\mathrm{S}$ protein SARS-CoV-2 since it nearly matches the one of SARS-CoV, enables the creation of efficient SARS-CoV-2 vaccines to use existing $\mathrm{S}$ protein information. In a limited number of COVID-19 patients, the potential usefulness of the $\mathrm{S}$ protein as the vaccine was discovered to neutralize antibodies against RBD and the $\mathrm{N}$-terminal domain of S proteins [34]. The mRNA serves as a guide from the protein-encoding of DNA to the ribosome translator proteins. The two types of mRNA vaccination platforms are mRNA self-amplifying and non-replicating mRNA. mRNA encoding not only the essential antigen but also viral mRNA replicates the natural infection of a virus but maintains only a short synthetic viral mRNA encoding just the essential antigen [35-36]. Due to its safety, effectiveness, short vaccine production time, and cost-effective production, these vaccinations are a promising substitute for traditional vaccine techniques. Antigen evaluation, sequence optimization, changed nucleotide screening; delivery system optimization, safety evaluation, and immunological evaluation are all steps in the development of the mRNA vaccine [37]. Immune responses, both cellular and humoral, are strongly induced by mRNA vaccines. As the DNA of the host cannot be interfered with and doesn't require the entire virus, this is just a transitory message carrier; it is relatively safe and efficient. There is presently no mRNA-based vaccination available. A Phase 1 clinical trial (NCT04283461) has so far been started using a Modern-/NIAID-produced SARS-CoV-2 mRNA (mRNA-1273, which encodes $\mathrm{S}$ protein) $[38,39]$. "Bluebird Biopharmaceutical Company" uses two different techniques to develop candidates for mRNA vaccination. The first is using mRNA to encode the protein $\mathrm{S}$ virus and the RBD domain. The second is to express in vivo particles similar to viruses. Candidate, a self-replicating mRNA vaccination in preclinical tests presently underway, has been produced by "Duke-Nus Medical School and Arcturus Therapeutics". Pfizer and BioNTech are involved in the development of BNT1622, a candidate for mRNA vaccination [40].Currently, in clinical examination, there have been six COVID-19 vaccinations as well as nineteen preclinical assessment candidates developed using the RNA platform [41].

\section{Current SARS-CoV-2 Vaccines Platforms}

\subsection{Inactivated Whole-Virus Vaccine}

These are created entirely by deactivating or killing the pathogen mainly induces protective antibodies on the surface of the virus against hemagglutinin glycoprotein epitopes when injected into the host. Despite the whole pathogen, subunit formulations consist mainly of a portion of the killed pathogen which is utilized more often as compared to alternative formulations because of the possible connection of increased formulation. Such vaccinations seem to generate a lesser immunological response as compared to live attenuated vaccinations, such that an adequate immune response is needed by adjuvants [42]. It has several hosts' antigenic components and can induce a variety of Immunologic reactions to the pathogen. There are many benefits to the inactivated whole-virus, such as cost-effective, secure \& reliable, and not occurred genetic modification [43]. A preclinical assessment is now undergoing for several COVID-19 vaccine candidates [44] (table 1). 
Table 1. COVID-19 vaccines and preclinical evaluation candidates with vaccines developing countries. Sources: who.int

\begin{tabular}{|c|c|c|}
\hline $\begin{array}{l}\text { IN PHASE III CLINICAL EVALUATION - } \\
\text { IMPORTANT CANDIDATE VACCINES }\end{array}$ & $\begin{array}{l}\text { VACCINE ADVANCED } \\
\text { PLATFORM } \\
\end{array}$ & $\begin{array}{c}\text { GEOGRAPHICAL LOCATION OF } \\
\text { PHASE III STUDIES }\end{array}$ \\
\hline $\begin{array}{c}\text { Wuhan Institute of Biological Products/ } \\
\text { Sinopharm }\end{array}$ & Inactivated virus & UAE \\
\hline Sinovac & Inactivated virus & Brazil \\
\hline Bharat Biotech & Inactivated virus & India \\
\hline $\begin{array}{c}\text { Beijing Institute of Biological Products/ } \\
\text { Sinopharm }\end{array}$ & Inactivated virus & China \\
\hline $\begin{array}{c}\text { CanSino Biological Inc./ } \\
\text { Beijing Institute of Biotechnology }\end{array}$ & Viral vector & Pakistan \\
\hline University of Oxford/AstraZeneca & Viral vector & USA \\
\hline Janssen Pharmaceutical Companies & Viral vector & $\begin{array}{c}\text { Brazil,USA, Peru,Colombia, } \\
\text { Philippines, Mexico, South } \\
\text { Africa }\end{array}$ \\
\hline Gamaleya Research Institute & Viral vector & Russia \\
\hline $\begin{array}{l}\text { Anhui Zhifei Longcom Biopharma/Institute of } \\
\text { Microbiology, Chinese Academy of Sci. }\end{array}$ & Protein-subunit & China \\
\hline Novavax & Protein-subunit & UK \\
\hline BioNTech/Fosun Pharma/Pfizer & RNA & USA,Brazil,Argentina \\
\hline Medicago Inc & VLP & Canada \\
\hline Moderna/NIAID & RNA & USA \\
\hline
\end{tabular}

\subsection{Live-Attenuated Vaccines}

The most popular conventional technique consisting of deliberately weakened live pathogens that can no longer infect but stimulate immunological response and therefore imitate the natural infection characteristics. It can cause immune responses, cellular as well as humoral. Live intranasal attenuated vaccinations induce IgA secretion and thus have local mucosal immunity. Three COVID-19 vaccine subjects are currently being developed using this platform in the preclinical evaluation stage $[45,46]$ (Table 2).

Table 2. List of live attenuated candidate vaccines developed against SARS-CoV.

\begin{tabular}{|c|c|c|}
\hline $\begin{array}{c}\text { Condition or } \\
\text { disease }\end{array}$ & Intervention/treatment & $\begin{array}{c}\text { Preclinical } \\
\text { evaluation stage }\end{array}$ \\
\hline SAR CoV & Biological: COVI-VAC & Phase-1 \\
\hline SAR CoV & $\begin{array}{c}\text { Nsp16 mutant lacking } \\
\text { 2'-OMTase }\end{array}$ & Pre-Clinical \\
\hline SAR CoV & SARS-CoV MA- $\Delta$ ExoN & Pre-Clinical \\
\hline
\end{tabular}

Source: who.int

\subsection{Subunit Vaccines}

Pathogen-derived proteins (antigens) that may induce immunogenicity in the host immune system are included in the subunit vaccinations. This vaccination is secure, reliable and simple to make using recombinant DNA technology, but it does require an adjuvant to enhance immune reaction [47]. The potential S-protein vaccination has been developed by Novavax, Inc. To date, "Clover Biopharmaceuticals" developed the $\mathrm{S}$ protein trimer vaccine for COVID-19 by utilising the Trimer-Tag(C) technology patent [48]. Since S protein RBD binds directly to the host's ACE2 receptor, RBD cells generate particular antibodies which may effectively inhibit and limit the invasion of the virus. The RBD antigen is in most vaccinations presently developed in the SARS-CoV-2 subunit. In monkey research, recombinant RBD protein lowers lung and oropharynx virus load effectively, as well as preventing viral pneumonia with MERS-CoV [49]. Similarly, it has been agreed in various studies that the S1 protein and/or RBD portion of SARS-CoV-2 should be considered the foremost antigen in COVID-19 vaccine production studies [50].

\subsection{Synthetic Peptide or Epitome Vaccine}

Such vaccines have been generated chemically from antigen fragments that evoke an immunological response. Such vaccinations are affordable, consistent and easily prepared. However, the antigen modification and the adjuvant needed during the preparation are seen to be low immunogenic. Antigen fragments are involved with B and/or Tepitope and alter the sensitivity of the immune reaction. At now, SARS-CoV-2 epitopes, a group of B and $\mathrm{T}$ detached from $\mathrm{S} \& \mathrm{~N}$ SARS-Cov proteins, are mostly retained as epitopes and may assist in the production of covid-19 vaccines [51]. A pharmaceutical company such as Generex Biotechnology, have produced peptide-based SARS-CoV-2 virus vaccines by manufacturing synthetic peptides which replicate essential antigens from a chemical virus [52].

\subsection{Viral Vector-Based Vaccine}

Among the potential and front-running contender Covid-19, 57 vector-based and live attenuated virus 
candidates from 11 companies have replication competence levels and replication-deficient viruses [53]. The delivery of an antigen encoded with an unrelated, modified virus is dependent upon Virus Vector-based Vaccines. This procedure employs live (replicated but usually attenuated) or non-replicating vectors with $\mathrm{Ad}$ (Adenovirus) vectors, measles virus, VSV and modified Ankara vaccine being the most frequently employed (MVA) [54]. Up to 7-8 $\mathrm{kb}$ of adenovirus can be inserted, promoting most antigens as a multivalent vaccination. Ad5 (Add Type 5) is frequently utilized and has been shown to have a better potential for inducing extremely robust CD4+ \& CD8+ T cells and antibody reactions [55].

\subsection{DVs (DNA Vaccine)}

DVs contain a plasmid that needs a unique gene which encodes the pathogenic antigens. The plasmid containing bacteria of the desired gene has been transferred to the host and to the antigenic protein that is usually stimulated by the pathogenic organisms activates the immune system was DVs elicit both the immune system that is humoral and cell-mediated. DVs produce a long-term immunity to prevent subsequent pathogens. DVs are extremely long-lasting, may be produced for weeks because no fermentation or culture is needed; the synthetic methods are employed instead and clinical tests are carried out within months, and the DNA vaccine is presently not authorized on the market [56]. Two decades ago, DNA-based vaccines were initiated and such vaccines are non-replicating as well as non-infectious. They are easy to produce in a short time and are both reliable as well as economical. However, they impart the host long-term immunogenicity, because of their poor immunogenic properties; when employed in humans, they retain hopelessness. The host enzymes also breakdown quickly and there is always the potential of incorporating them into host DNA. The potential in human trials has yet to be identified, but effectiveness has been proved in animal models. Currently, under clinical evaluation, there are four COVID-19 vaccination and 14 pre-clinical assessment candidates produced with the DNA framework [57].

\subsection{Plant-based Vaccines}

The molecular farming of the VLPs is more stable since native particles can't replicate in humans and huge volume can be achieved. Utilizing tobacco plants, Medicago Inc. (Québec,Canada) manipulated the VLP platform 10 million H1N1 flu vaccine shots are produced within one month [58-59]. Medicago has started VLP-based SARS-CoV-2 plant vaccinations [60]. Additionally, the tobacco plant genome (Nicotiana benthamiana) has been examined by experts from Queensland University of Technology and is using the plant genome sequence for COVID-19 growth. The University of San Diego
California is also investigating the plant-based development and the combination of molecular molecules for COVID-19 vaccinations [61]. The virus can infect the legumes however it does not infect human beings. SARS-CoV-2 is intended to provide an appropriate immune response [62]. Though vaccines of the third generation may revolutionize the vaccination industry, prior to practical deployment, the problems associated with vaccinations of the third generation need to be solved. Third-generation vaccines originate without infections, are modulative, produce sufficient immune reactions and have also reached clinical Phase III studies with a few prospective clinical candidates; to date, however, plant host expression and no human for Antigen selection have been made accessible, dose accuracy, and protocols for GMP development are the challenges that need to be tackled in the future. Overcoming these constraints could allow the future availability of safe, stable, reliable, and cost-effective plant-based vaccinations, along with the COVID-19 vaccination [63-67].

\subsection{Recombinant Protein-Based Vaccine}

Compared with all the platforms used for vaccine development, this is the most common because it offers several benefits such as safety patterns and cost-effective manufacturing but long-term immune responses are needed for adjuvants. For recombinant protein, there are some examples of Vaccines that are used in humans, such as the hepatitis B vaccine (HBV). Extremely pure recombinant proteins from different etiological agents were the most popular choices investigated for vaccinations. Various genes are being processed as recombinant proteins (Cloned, expressed \& purified in several expression systems) and manufactured as vaccines from viral particles encoding the antigenic determinant. Antigens experiencing post-translational alterations can be expressed in mammalian cells, whereas antigens undergoing post-translational changes can be expressed in bacteria [68]. There are currently 13 candidates for COVID-19 vaccinations in the clinical assessment phase and 55 candidates for COVID-19 vaccinations in the pre-clinical assessment phase, formed as a recombinant [69].

\section{Conclusion and future perspectives}

A significant quantity of studies has been conducted in a relatively short period to obtain a good understanding of the structure of SARS CoV-2. The underlying pathological basis of vaccine design that may be considered for the manufacture of SARS-CoV-2infection vaccines, as well as numerous vaccine development platforms that are being employed, have been addressed in this comprehensive review. We anticipate that this 
research will increase public awareness of the SARS-CoV-2 vaccination and, as a result, enhance such infection management. It also provides information on the present state of vaccine production as well as findings from the study at various stages.

\section{Declaration}

\section{Conflicts of Interest}

Authors declare that there exist no commercial or financial relationships that could, in any way, lead to a potential conflict of interest.

\section{Acknowledgments}

The authors are grateful to the host institute-Government Pharmacy College, Sajong, Government of Sikkim to give such advanced facilities to collect all the essential data for this systematic review. Also thankful to Department of Pharmaceutical Sciences, Dibrugarh University, Dibrugarh, Assam and Department of Pharmaceutical Technology, University of North Bengal, West Bengal.

\section{Author contributions}

S.B, contributed for collecting, drafting and formatting this review article and communicating with scientific esteemed journal having good reputation in the scientific fields. S.B, responsible formatting of the references as per the journal standard guidelines. B.B.K and P.P completed the overall screening of the write up. All the Authors have read and approved the manuscript.

\section{Funding}

This work did not receive any specific grant from funding agencies in the public, commercial, or not-for-profit sectors.

\section{REFERENCES}

[1] Sonia Navas-Martín \& Susan R Weiss (2004) Coronavirus replication and pathogenesis: Implications for the recent outbreak of severe acute respiratory syndrome (SARS), and the challenge for vaccine development, Journal of Neurovirology, 10:2, 75-85, DOI: 10.1080/135502804902 80292 .

[2] Wong SK, Li W, Moore MJ, Choe H, Farzan M. A 193-amino acid fragment of the SARS coronavirus S protein efficiently binds angiotensin-converting enzyme 2 . J Biol Chem. 2004; 279(5): 3197-201. doi: 10.1074/jbc.C300520200.
[3] Masters PS. The molecular biology of coronaviruses. Adv Virus Res. 2006; 66: 193-292. doi: 10.1016/S0065-3527(06)66005-3.

[4] Knoops K, Kikkert M, Worm SH, Zevenhoven-Dobbe JC, van der Meer Y, Koster AJ, Mommaas AM, SnijderEJ. SARS-coronavirus replication is supported by a reticulovesicular network of modified endoplasmic reticulum. PLoS Biol. 2008; 6(9): e226. doi: 10.1371/journal.pbio.0060226.

[5] Lu G, Hu Y, Wang Q, Qi J, Gao F, Li Y, Zhang Y, Zhang W, Yuan Y, Bao J, Zhang B, Shi Y, Yan J, Gao GF. Molecular basis of binding between novel human coronavirus MERS-CoV and its receptor CD26. Nature. 2013; 500(7461):227-31. doi: 10.1038/nature12328.

[6] Ling Y, Xu SB, Lin YX, Tian D, Zhu ZQ, Dai FH, Wu F, Song ZG, Huang W, Chen J, et al. Persistence and clearance of viral RNA in 2019 novel coronavirus disease rehabilitation patients. Chin Med J (Engl). 2020; 133(9):1039-1043. doi: 10.1097/CM9.0000000000000774.

[7] Shulla, A., et al., A transmembrane serine protease is linked to the severe acute respiratory syndrome coronavirus receptor and activates virus entry. Journal of virology, 2011. 85(2): 873-882. DOI: 10.1128/JVI.02062-10.

[8] Kim E, Okada K, Kenniston T, Raj VS, AlHajri MM, Farag EA, AlHajri F, Osterhaus AD, Haagmans BL, Gambotto A. Immunogenicity of an adenoviral-based Middle East Respiratory Syndrome coronavirus vaccine in BALB/c mice. Vaccine. 2014; 32(45): 5975-82. doi: 10.1016/j.vaccine.2014.08.058.

[9] Bonam, S. R., Kotla, N. G., Bohara, R. A., Rochev, Y., Webster, T. J., \& Bayry, J. (2020). Potential immuno-nanomedicine strategies to fight COVID-19 like pulmonary infections. Nano Today, 101051.

[10] Buchholz UJ, Bukreyev A, Yang L, Lamirande EW, Murphy BR, Subbarao K, Collins PL. Contributions of the structural proteins of severe acute respiratory syndrome coronavirus to protective immunity. Proc Natl AcadSci U S A. 2004;101(26):9804-9. doi: 10.1073/pnas.0403492101.

[11] Traggiai E, Becker S, Subbarao K, Kolesnikova L, Uematsu Y, Gismondo MR, Murphy BR, Rappuoli R, Lanzavecchia A. An efficient method to make human monoclonal antibodies from memory B cells: potent neutralization of SARS coronavirus. Nat Med. 2004;10(8):871-5. doi: 10.1038/nm1080.

[12] Corti D, Zhao J, Pedotti M, Simonelli L, Agnihothram S, Fett C, Fernandez-Rodriguez B, Foglierini M, Agatic G, Vanzetta F, Gopal R, Langrish CJ, Barrett NA, Sallusto F, Baric RS, Varani L, Zambon M, Perlman S, Lanzavecchia A. Prophylactic and postexposure efficacy of a potent human monoclonal antibody against MERS coronavirus. Proc Natl AcadSci U S A. 2015;112(33):10473-8. doi: 10.1073/pnas. 1510199112 .

[13] Walls AC, Park YJ, Tortorici MA, Wall A, McGuire AT, Veesler D. Structure, Function, and Antigenicity of the SARS-CoV-2 Spike Glycoprotein. Cell. 2020; 181(2):281-292.e6. doi: 10.1016/j.cell.2020.02.058.

[14] Wrapp D, Wang N, Corbett KS, Goldsmith JA, Hsieh CL, Abiona O, Graham BS, McLellan JS. Cryo-EM structure of the 2019-nCoV spike in the prefusion conformation. 
Science. 2020; 367(6483): 1260-1263. doi: 10.1126/scienc e.abb2507.

[15] Jaimes JA, Millet JK, Whittaker GR. Proteolytic Cleavage of the SARS-CoV-2 Spike Protein and the Role of the Novel S1/S2 Site. iScience. 2020;23(6):101212. doi: 10.1016/j.isci.2020.101212.

[16] Bestle D, Heindl MR, Limburg H, Van Lam van T, Pilgram O, Moulton H, Stein DA, Hardes K, Eickmann M, Dolnik O, Rohde C, Klenk HD, Garten W, Steinmetzer T, Böttcher-Friebertshäuser E. TMPRSS2 and furin are both essential for proteolytic activation of SARS-CoV-2 in human airway cells. Life Sci Alliance. 2020;3(9):e202000786. doi: 10.26508/1sa.202000786.

[17] Liu, Z., Xia, M., Chai, Z., \& Wang, D. (2020). Tracing driving forces responsible for the remarkable infectivity of 2019-nCoV: 1. receptor binding domain in its bound and unbound states. Physical Chemistry Chemical Physics. https://doi.org/10.1039/D0CP04435K.

[18] Hoffmann M, Kleine-Weber H, Schroeder S, Krüger N, Herrler T, Erichsen S, SchiergensTS, Herrler G, Wu NH, Nitsche A, Müller MA, Drosten C, Pöhlmann S. SARS-CoV-2 Cell Entry Depends on ACE2 and TMPRSS2 and Is Blocked by a Clinically Proven Protease Inhibitor. Cell. 2020; 181(2): 271-280. e8. doi: 10.1016/j.cell.2020.02.052.

[19] Hatesuer B, Bertram S, Mehnert N, Bahgat MM, Nelson PS, Pöhlmann S, Schughart K. Tmprss2 is essential for influenza $\mathrm{H} 1 \mathrm{~N} 1$ virus pathogenesis in mice. PLoSPathog. 2013;9(12):e1003774. doi: 10.1371/journal.ppat.1003774.

[20] Yamamoto, M., Matsuyama, S., Li, X., Takeda, M., Kawaguchi, Y., Inoue, J. I., \& Matsuda, Z. (2016). Identification of nafamostat as a potent inhibitor of Middle East respiratory syndrome coronavirus $\mathrm{S}$ protein-mediated membrane fusion using the split-protein-based cell-cell fusion assay. Antimicrobial agents and chemotherapy, 60(11), 6532-6539. DOI: 10.1128/AAC.01043-16.

[21] Jang S, Rhee JY. Three cases of treatment with nafamostat in elderly patients with COVID-19 pneumonia who need oxygen therapy. Int J Infect Dis. 2020;96:500-502. doi: 10.1016/j.ijid.2020.05.072.

[22] Monteil V, Kwon H, Prado P, Hagelkrüys A, Wimmer RA, Stahl M, Leopoldi A, Garreta E, Hurtado Del Pozo C, Prosper F, et al., Inhibition of SARS-CoV-2 Infections in Engineered Human Tissues Using Clinical-Grade Soluble Human ACE2. Cell. 2020; 181(4): 905-913. e7. doi: 10.1016/j.cell.2020.04.004.

[23] Liu, Y., Ning, Z., Chen, Y. et al. Aerodynamic analysis of SARS-CoV-2 in two Wuhan hospitals. Nature 582, 557560 (2020). https://doi.org/10.1038/s41586-020-2271-3.

[24] Shen C, Wang Z, Zhao F, Yang Y, Li J, Yuan J, Wang F, Li D, Yang M, Xing L, et al., Treatment of 5 Critically Ill Patients With COVID-19 With Convalescent Plasma. JAMA. 2020; 323(16): 1582-1589. doi: 10.1001/jama.202 0.4783 .

[25] Duan K, Liu B, Li C, Zhang H, Yu T, Qu J, Zhou M, Chen L, Meng S, Hu Y, et al., Effectiveness of convalescent plasma therapy in severe COVID-19 patients. Proc Natl AcadSci U S A. 2020; 117(17): 9490-9496. doi: $10.1073 /$ pnas. 2004168117 .
[26] Li L, Zhang W, Hu Y, Tong X, Zheng S, Yang J, Kong Y, Ren L, Wei Q, Mei H, et al., Effect of Convalescent Plasma Therapy on Time to Clinical Improvement in Patients With Severe and Life-threatening COVID-19: A Randomized Clinical Trial. JAMA. 2020; 324(5): 460-470. doi: 10.1001/jama.2020.10044.

[27] Gharbharan, A., Jordans, C. C., GeurtsvanKessel, C., den Hollander, J. G., Karim, F., Mollema, F. P., ... \& Hassing, R. J. (2020). Convalescent Plasma for COVID-19. A randomized clinical trial. MEDRxiv. doi: https://doi.org/10 $.1101 / 2020.07 .01 .20139857$.

[28] Cortegiani A, Ippolito M, Ingoglia G, Iozzo P, Giarratano A, Einav S. Update I. A systematic review on the efficacy and safety of chloroquine/hydroxychloroquine for COVID-19. J Crit Care. 2020; 59: 176-190. doi: 10.1016/j.jcrc.2020.06.019.

[29] Cavalcanti AB, ZampieriFG, Rosa RG, Azevedo LCP, Veiga VC, Avezum A, Damiani LP, Marcadenti A, Kawano-Dourado L, Lisboa T, et al., Hydroxychloroquine with or without Azithromycin in Mild-to-Moderate Covid-19. N Engl J Med. 2020;383(21):2041-2052. doi: 10.1056/NEJMoa2019014.

[30] Chorin E, Wadhwani L, Magnani S, Dai M, Shulman E, Nadeau-Routhier C, Knotts R, Bar-Cohen R, Kogan E, Barbhaiya C, et al., QT interval prolongation and torsade de pointes in patients with COVID-19 treated with hydroxychloroquine/azithromycin. Heart Rhythm. 2020;17(9):1425-1433. doi: 10.1016/j.hrthm.2020.05.014.

[31] Chi Y, Ge Y, Wu B, Zhang W, Wu T, Wen T, Liu J, Guo X, Huang C, Jiao Y, Zhu F, Zhu B, Cui L. Serum Cytokine and Chemokine Profile in Relation to the Severity of Coronavirus Disease 2019 in China. J Infect Dis. 2020;222(5):746-754. doi: 10.1093/infdis/jiaa363.

[32] Xu X, Han M, Li T, Sun W, Wang D, Fu B, Zhou Y, Zheng X, Yang Y, Li X, Zhang X, Pan A, Wei H. Effective treatment of severe COVID-19 patients with tocilizumab. Proc Natl AcadSci U S A. 2020;117(20):10970-10975. doi: 10.1073/pnas.2005615117.

[33] Liu L, Wang P, Nair MS, Yu J, Rapp M, Wang Q, Luo Y, Chan JF, Sahi V, Figueroa A, Guo XV, Cerutti G, Bimela J, Gorman J, Zhou T, Chen Z, Yuen KY, Kwong PD, Sodroski JG, Yin MT, Sheng Z, Huang Y, Shapiro L, Ho DD. Potent neutralizing antibodies against multiple epitopes on SARS-CoV-2 spike. Nature. 2020;584(7821):450-456. doi: 10.1038/s41586-020-2571-7.

[34] Pardi N, Hogan MJ, Porter FW, Weissman D. mRNA vaccines - a new era in vaccinology. Nat Rev Drug Discov. 2018; (4):261-279. doi: 10.1038/nrd.2017.243.

[35] Dhama, K., Sharun, K., Tiwari, R., Dadar, M., Malik, Y. S., Singh, K. P., \&Chaicumpa, W. (2020). COVID-19, an emerging coronavirus infection: advances and prospects in designing and developing vaccines, immunotherapeutics, and therapeutics. Human vaccines \&immunotherapeutics, $1-7$.

[36] Zhang C, Maruggi G, Shan H, Li J. Advances in mRNA Vaccines for Infectious Diseases. Front Immunol. 2019;10:594. doi: 10.3389/fimmu.2019.00594.

[37] Amanat F, Krammer F. SARS-CoV-2 Vaccines: Status Report. Immunity. 2020; 52(4): 583-589. doi: 10.1016/j.immuni.2020.03.007. 
[38] Saxena, S. K., Kumar, S., Maurya, V. K., Sharma, R., Dandu, H. R., \& Bhatt, M. L. (2020). Current Insight into the Novel Coronavirus Disease 2019 (COVID-19). In Coronavirus Disease 2019 (COVID-19) (pp. 1-8). Springer, Singapore.

[39] World Health Organization, 2020.(Accessed 30 Nov 2020).

[40] Sekimukai H, Iwata-Yoshikawa N, Fukushi S, Tani H, Kataoka M, Suzuki T, Hasegawa H, Niikura K, Arai K, Nagata N. Gold nanoparticle-adjuvanted S protein induces a strong antigen-specific IgG response against severe acute respiratory syndrome-related coronavirus infection, but fails to induce protective antibodies and limit eosinophilic infiltration in lungs. MicrobiolImmunol. 2020;64(1):33-51. doi: $10.1111 / 1348-0421.12754$.

[41] Xia, S., Liu, M., Wang, C. et al. Inhibition of SARS-CoV-2 (previously 2019-nCoV) infection by a highly potent pan-coronavirus fusion inhibitor targeting its spike protein that harbors a high capacity to mediate membrane fusion. Cell Res 30, 343-355 (2020). https://doi.org/10.1038/s4142 2-020-0305-x.

[42] Yan R, Zhang Y, Li Y, Xia L, Guo Y, Zhou Q. Structural basis for the recognition of SARS-CoV-2 by full-length human ACE2. Science. 2020;367(6485):1444-1448. doi: 10.1126/science.abb2762.

[43] Zhang R, Li Y, Zhang AL, Wang Y, Molina MJ. Identifying airborne transmission as the dominant route for the spread of COVID-19. Proc Natl AcadSci U S A. 2020; 117(26): 14857-14863. doi: 10.1073/pnas.2009637117.

[44] Rawat K, Kumari P, Saha L. COVID-19 vaccine: A recent update in pipeline vaccines, their design and development strategies. Eur J Pharmacol. 2020: 173751. doi: 10.1016/j.ejphar.2020.173751.

[45] Furuya Y. Return of inactivated whole-virus vaccine for superior efficacy. Immunol Cell Biol. 2012;90(6):571-8. doi: $10.1038 /$ icb.2011.70.

[46] Barria MI, GarridoJL, Stein C, Scher E, Ge Y, Engel SM, Kraus TA, Banach D, Moran TM. Localized mucosal response to intranasal live attenuated influenza vaccine in adults. J Infect Dis. 2013; 207(1): 115-24. doi: 10.1093/infdis/jis641.

[47] World Health Organization, 2020. (Accessed 29 Nov 2020).

[48] Liljeqvist S, Ståhl S. Production of recombinant subunit vaccines: protein immunogens, live delivery systems and nucleic acid vaccines. J Biotechnol. 1999; 73(1): 1-33. doi: 10.1016/s0168-1656(99)00107-8.

[49] Uddin M, Mustafa F, Rizvi TA, Loney T, Suwaidi HA, Al-MarzouqiAHH, Eldin AK, Alsabeeha N, Adrian TE, Stefanini C, Nowotny N, Alsheikh-Ali A, Senok AC. SARS-CoV-2/COVID-19: Viral Genomics, Epidemiology, Vaccines, and Therapeutic Interventions. Viruses. 2020;12(5):526. doi: 10.3390/v12050526.

[50] Zhang J, Zeng H, Gu J, Li H, Zheng L, Zou Q. Progress and Prospects on Vaccine Development against SARS-CoV-2. Vaccines (Basel). 2020; 8(2): 153. doi: $10.3390 /$ vaccines 8020153 .

[51] Wang Y, Wang L, Cao H, Liu C. SARS-CoV-2 S1 is superior to the RBD as a COVID-19 subunit vaccine antigen. J Med Virol. 2020:10.1002/jmv.26320. doi: 10.1002/jmv.26320.

[52] Kuo TY, Lin MY, Coffman RL, Campbell JD, Traquina P, Lin YJ, Liu LT, Cheng J, Wu YC, Wu CC, et al. Development of CpG-adjuvanted stable prefusion SARS-CoV-2 spike antigen as a subunit vaccine against COVID-19. Sci Rep. 2020; 10(1): 20085. doi: 10.1038/s41598-020-77077-z.

[53] Qi X, Ke B, Feng Q, Yang D, Lian Q, Li Z, Liao G, (2020). Construction and immunogenic studies of amFc fusion receptor binding domain (RBD) of spike protein as a subunit vaccine against SARS-CoV-2 infection. Chemical Communications, 56(61),8683-8686.https://doi.org/10.103 9/D0CC03263H

[54] Thanh Le T, Andreadakis Z, Kumar A, Gómez Román R, Tollefsen S, Saville M, Mayhew S. The COVID-19 vaccine development landscape. Nat Rev Drug Discov. 2020;19(5):305-306. doi: 10.1038/d41573-020-00073-5.

[55] Rahman MS, Hoque MN, Islam MR, Akter S, RubayetUlAlamASM, Siddique MA, Saha O, Rahaman MM, Sultana M, Crandall KA, Hossain MA. Epitope-based chimeric peptide vaccine design against $\mathrm{S}, \mathrm{M}$ and $\mathrm{E}$ proteins of SARS-CoV-2, the etiologic agent of COVID-19 pandemic: an in silico approach. PeerJ. 2020;8:e9572. doi: 10.7717/peerj. 9572 .

[56] Covid-19 tracker, London School of Hygiene \&Tropical Medicine. https://vaclshtm. shinyapps.io/ncov_vaccine_lan dscape/. Accessed on 2 Dec 2020.

[57] Rauch, S., Jasny, E., Schmidt, K. E., \&Petsch, B. (2018). New vaccine technologies to combat outbreak situations. Frontiers in immunology, 9, 1963. doi10.3389/fimmu.2018 .01963 .

[58] Hancock, G., Hellner, K., \& Dorrell, L. (2018). Therapeutic HPV vaccines. Best Practice \& Research Clinical Obstetrics \& Gynaecology, 47, 59-72.

[59] Hobernik D, Bros M. DNA Vaccines-How Far From Clinical Use? Int J Mol Sci. 2018;19(11):3605. doi: 10.3390/ijms 19113605 .

[60] Oosterhuis K, van den Berg JH, Schumacher TN, Haanen JB. DNA vaccines and intradermal vaccination by DNA tattooing. Curr Top MicrobiolImmunol. 2012;351:221-50. doi: 10.1007/82 2010_117.

[61] Le, T. T., Andreadakis, Z., Kumar, A., Roman, R. G., Tollefsen, S., Saville, M., \& Mayhew, S. (2020). The COVID-19 vaccine development landscape. Nat Rev Drug Discov, 19(5), 305-306.

[62] Rybicki EP. Plant molecular farming of virus-like nanoparticles as vaccines and reagents. Wiley Interdiscip Rev NanomedNanobiotechnol. 2020;12(2):e1587. doi: 10.1002/wnan.1587.

[63] D'Aoust MA, Couture MM, Charland N, Trépanier S, Landry N, Ors F, Vézina LP. The production of hemagglutinin-based virus-like particles in plants: a rapid, efficient and safe response to pandemic influenza. Plant Biotechnol J. 2010; 8(5): 607-19. doi: 10.1111/j.1467-7652.2009.00496.x.

[64] iBio. iBio announces development of proprietary 
COVID-19 vaccine candidates. 2020. https://wwwglobene wswirecom/newsrelease/2020/03/18/2002546/0/en/iBio-A nnounces-Developmentof-Proprietary-COVID-19-Vaccine -Candidateshtml (Accessed 4 Dec 2020).

[65] ISAAA. Nanoengineers combine molecular farming and advanced manufacturing to develop COVID-19 vaccine. 2020. http://wwwisaaaorg/kc/cropbiotechupdate/article/def aultasp?ID=18090(Aceessed: 1 July 2020).

[66] Chowdhury MA, Hossain N, Kashem MA, Shahid MA, Alam A. Immune response in COVID-19: A review. J Infect Public Health. 2020; 13(11): 1619-1629. doi: 10.1016/j.jiph.2020.07.001
[67] Dhama K, Natesan S, Iqbal Yatoo M, Patel SK, Tiwari R, Saxena SK, Harapan H. Plant-based vaccines and antibodies to combat COVID-19: current status and prospects. Hum VaccinImmunother. 2020; 1-8. doi: $10.1080 / 21645515.2020 .1842034$.

[68] Kumar A, MeldgaardTS, Bertholet S. Novel Platforms for the Development of a Universal Influenza Vaccine. Front Immunol. 2018; 9:600. doi: 10.3389/fimmu.2018.00600.

[69] Nascimento IP, Leite LC. Recombinant vaccines and the development of new vaccine strategies. Braz J Med Biol Res. 2012; 45(12): 1102-11. doi: 10.1590/s0100-879x2012 007500142 . 